\title{
Deposição e Distribuição de Calda de Pulverização em Plantas de Feij oeiro (Phaseolus vulgaris) e Capim-Braquíria (Brachiaria decumbens)
}

\author{
Deposition and Distribution of Spraying Solution on Phaseolus vulgaris and \\ Brachiaria decumbens
}

MACIEL, C.D.G. ${ }^{2}$, SOUZA, R.T. ${ }^{2}$, SILVA, R.H. ${ }^{2}$, VELINI, E.D. ${ }^{3}$ e LEMOS, L.B. ${ }^{3}$

\begin{abstract}
RESUMO - Com o objetivo de avaliar a deposição e distribuição de solução traçante em plantas de feijoeiro e capim-braquiária, foi conduzido experimento no NuPAM-FCA/ UNESP, campus de Botucatu-SP, utilizando um simulador de pulverização em ambiente controlado. Os tratamentos utilizados foram: bico jato plano XR Teejet (XR110.02VS) + surfactante Aterbane BR (0,5\% v/v); bico jato cônico Conejet (TXVK-4) + surfactante Aterbane BR $(0,5 \%$ v/v); bico jato plano XR Teejet (XR110.02VS); e bico jato cônico Conejet (TXVK-4). Em todos os tratamentos foi aplicada uma solução de $\mathrm{NaCl}(0,5 \% \mathrm{p} / \mathrm{v})+$ corante Poliglow laranja $(0,5 \%$ $\mathrm{p} / \mathrm{v})+$ mancozeb $(0,5 \% \mathrm{p} / \mathrm{v})$. As unidades experimentais constituíram-se de vasos com duas plantas-alvo de capim-braquiária posicionadas sob uma planta-alvo de feijoeiro. A visualização da distribuição das gotas nas folhas de capim-braquiária foi efetuada com auxílio de luz negra, e o depósito da calda na superfície das plantas foi quantificado através da condutividade elétrica da solução aplicada e coletada por meio de lavagem de ambos os alvos. Os bicos de pulverização, jato plano (XR Teejet) e cônico (Conejet), não apresentaram diferença no depósito nos folíolos totais de feijoeiro quando submetidos a mesma condição de calda de pulverização. No entanto, o bico jato plano XR Teejet (XR110.02VS) e o bico jato cônico Conejet (TXVK-4) proporcionaram aumento de 67,1 e 61,5\% na deposição da calda em relação a área foliar e 106,4 e $66,9 \%$ para matéria seca, respectivamente, em relação ao bico jato plano XR Teejet (XR1 10.02VS) + surfactante Aterbane BR (0,5\% v/v) e ao bico jato cônico Conejet (TXVK-4) + surfactante Aterbane BR (0,5\% v/v). Para o capim-braquiária, o bico cônico Conejet proporcionou deposição superior e distribuição mais uniforme em relação ao jato plano XR Teejet.
\end{abstract}

Palavras-chave: alvo, bicos de pulverização, surfactante, condutividade elétrica.

ABSTRACT - An experiment was carried out at the NUPAM-FCA/UNESP, Botucatu Campus, São Paulo, Brazil, to estimate the deposition and distribution of a marker solution on the P. vulgaris and $\boldsymbol{B}$. decumbens plants, using a sprayer simulator under a controlled environment. The treatments were: nozzle fan jet XR Teejet (XR1 10.02VS) + surfactant (Aterbane BR - 0.5\% v/v); nozzle Conejet (TXVK-4) + surfactant (Aterbane BR - 0.5\% v/v); nozzle fan jet XR Teejet (XR1 10.02VS) and nozzle Conejet (TXVK-4). A solution of $\mathrm{NaCl}(0.5 \%)+$ Orange Poliglow colour $(0.5 \%)+$ mancozeb $(0.5 \%)$ was applied in all treatments. The experimental units consisted of pots with two B. decumbens target plants underneath one $\boldsymbol{P}$. vulgaris target plant. Droplet distribution over B. decumbens leaves was evaluated with black light, and deposition by electric conductivity of the sprayer solution collected by washing the targets in deionized water. The spraying nozzles, XR Teejet and Conejet, did not show deposition difference on $\boldsymbol{P}$. vulgaris leaves, under equal spray solution conditions. However, the nozzle with fan jet XR Teejet (XR1 10.02VS) and the nozzle Conejet (TXVK-4) provided, respectively, $67.1 \%$ and $61.5 \%$ increase on the leaf area deposition and $106,4 \%$ and $66.9 \%$ increase dry weight increase, when compared to the nozzle with fan jet XR Teejet (XR110.02VS) + surfactant (Aterbane BR - 0.5\% v/v) and the nozzle Conejet (TXVK-4) + surfactant (Aterbane BR - 0.5\% v/v). Nozzle Conejet provided higher uniform distribution, when compared to nozzle XR Teejet.

Key words: target, sprayer nozzle, surfactant, electric conductivity.

Recebido para publicação em 25/9/2000 e na forma revisada em 13/3/2001.

Alunos de Pós-Graduação em Agricultura da FCA/UNESP; ${ }^{3}$ Prof. Dr. Dep. Produção Vegetal da FCA/UNESP, Caixa Postal 237, 18603-970 Botucatu-SP.

Planta Daninha, Viçosa-MG, v.19, n.1, p.103-110, 2001 


\section{INTRODUÇÃO}

Os processos mecânicos na agricultura vêm sofrendo uma série de inovações e melhoramentos, de maneira a atender às necessidades cada vez maiores de se conseguir aumento na produtividade das culturas. Entre os vários eventos que constituem o processo de produção agrícola, a aplicação de defensivos agrícolas é um dos mais exigentes, pois atende não somente ao tratamento da área cultivada, como também cuidados com a preservação do meio ambiente (Christoffoleti, 1999).

No Brasil, a cultura do feijoeiro é uma das mais importantes, chegando-se a cultivar três safras em diferentes épocas do ano, ocupando a quarta área de plantio. Apesar da sua importância, a produtividade média no País deixa muito a desejar, em razão de diversos fatores fitotécnicos, incluindo a interferência das plantas daninhas (Deuber, 1997).

Hislop et al. (1987) relatam que os maiores objetivos em pesquisas com aplicação de defensivos são a definição do depósito em alvos biológicos e a identificação de métodos precisos de aplicação, os quais são desenvolvidos para permitir redução no volume de pulverização e/ou na dose de ingrediente ativo, sem perder a eficiência biológica.

Estudos referentes à deposição e distribuição das gotas produzidas por pontas de pulverização nas culturas e plantas daninhas são de grande importância na determinação da eficiência da aplicação dos produtos fitossanitários. No entanto, a utilização de alvos naturais em estudos de deposição, apesar de eles serem os preferidos, por constituírem fielmente as características do alvo estudado, apresenta complexibilidade e variabilidade natural, que afetam a retenção e o espalhamento do produto aplicado (Miller, 1993). Os bicos são considerados os componentes fundamentais de qualquer sistema de pulverização (Velini et al., 1995). A importância do conhecimento de suas características se deve ao fato de que são responsáveis por controlar a saída do líquido na quantidade desejada por unidade de tempo e espalhar as gotas formadas dentro de uma área delimitada (Silva, 1982). Portanto, a escolha incorreta das pontas de pulverização constituise numa das principais causas responsáveis pelo fracasso e desperdício de produto na aplicação de defensivos (Matuo, 1982; Pio, 1997).

A reflexão de gotas e a dificuldade de molhamento de muitas superfícies de plantas são consideradas sérios obstáculos na retenção de gotas e conseqüentemente na eficácia das pulverizações. Segundo Brazee et al. (1994), as gotas refletidas das superfícies das plantas normalmente apresentam menor captura e limitam a eficiência da aplicação. Além disso, Revees (1992) relata como exemplos de perdas a deriva, a volatilização, o escorrimento, a evaporação e a remoção pelo vento, que podem ser perfeitamente minimizadas por meio da modificação das gotas pulverizadas com a adição de adjuvantes às caldas dos produtos agroquímicos.

Matuo et al. (1989) reportam o uso dos surfactantes, ou agentes tensoativos, como substâncias que visam proporcionar uma deposição e retenção mais efetiva da pulverização no alvo tratado. Essas substâncias modificam as forças interfaciais por orientação de suas moléculas entre as interfaces, promovendo, assim, ajustamento mais intimo das moléculas de duas substâncias (Durigan, 1993).

Desse modo, a tecnologia de aplicação utilizada constitui-se em um dos fatores limitantes da eficiência de herbicidas e demais defensivos agrícolas, tornando-se necessário o constante aprimoramento das técnicas e dos equipamentos habitualmente utilizados nos sistemas de produção.

Este trabalho teve como objetivo avaliar o desempenho de deposição e distribuição da calda de pulverização em condição de pósemergência da cultura do feijoeiro e de plantas de capim-braquiária, utilizando-se dois modelos de pontas de pulverização, associadas ou não ao uso do surfactante Aterbane BR.

\section{MATERIAL E MÉTODOS}

O experimento foi desenvolvido na segunda quinzena de junho/1999, nas dependências do NuPAM (Núcleo de Pesquisas Avançadas em Matologia), pertencente ao Departamento de Produção Vegetal da FCA/UNESP, BotucatuSP.

O delineamento experimental utilizado foi o de blocos inteiramente casualizados, com 
quatro tratamentos e cinco repetições. Os tratamentos utilizados no experimento foram constituídos por dois tipos de pontas de pulverização, fazendo-se o uso de uma solução traçante adicionada ou não de surfactante. As pontas utilizadas foram: bico jato plano XR Teejet (XR1 10.02VS) e bico jato cônico Conejet (TXVK4). O surfactante utilizado foi o espalhante adesivo Aterbane BR, na dose de 0,5\% v/v. Ambos os modelos de pontas de pulverização foram submetidos às pressões de trabalho especificadas pelo fabricante, conforme suas respectivas recomendações, proporcionando volumes de aplicação de $185 \mathrm{~L} \mathrm{ha}^{-1}$ para o bico leque e $120 \mathrm{~L} \mathrm{ha}^{-1}$ para o bico cônico. Em todos os tratamentos foi aplicada uma solução traçante, constituída por $\mathrm{NaCl}(0,5 \% \mathrm{p} / \mathrm{v})+$ corante Poliglow laranja $(0,5 \% \mathrm{p} / \mathrm{v})+$ manzate $(0,5 \%$ $\mathrm{p} / \mathrm{v}$ ), com o objetivo de utilizar uma única calda de pulverização e obter, nas mesmas plantasalvo avaliadas, informações sobre a quantidade do traçante depositado, assim como sobre o comportamento da distribuição das gotas coloridas sobre as folhas.

Na aplicação da solução traçante utilizouse um simulador de pulverização, constituído por uma estrutura de sustentação metálica, que permite o acoplamento de um carrinho com uma barra de pulverização munida de quatro bicos espaçados de $50 \mathrm{~cm}$ e posicionada a $50 \mathrm{~cm}$ de altura das plantas-alvo, com deslocamento no sentido do comprimento da estrutura do equipamento. O tracionamento do sistema de pulverização foi realizado por um motor elétrico, através de correntes, e controlado por um modulador de freqüência, que permitiu trabalhar com velocidade constante e previamente determinada de $3,6 \mathrm{~km} \mathrm{~h}^{-1}$. A pressurização da solução traçante foi feita com ar comprimido, por um compressor localizado externamente à sala de pulverização, a qual promoveu pressão de trabalho constante durante a aplicação de cada tratamento. No momento da pulverização dos tratamentos, as condições climáticas na sala de pulverização apresentavam-se com temperatura e umidade relativa do ar de $24{ }^{\circ} \mathrm{C}$ e $69 \%$, respectivamente, e o ambiente de sala fechada não permitiu a interferência de ventos durante as pulverizações.

Anteriormente à aplicação, as unidades experimentais foram conduzidas em casa de vegetação e constituíram-se de vasos com $35 \mathrm{~cm}$ de diâmetro e capacidade para $5 \mathrm{~kg}$ de solo, nos quais foram cultivadas duas plantasalvo de capim-braquiária posicionadas sob uma planta-alvo de feijoeiro, cultivar IAPAR-81. No momento da aplicação, as plantas de capimbraquiária e de feijoeiro encontravam-se com seis folhas e cinco folhas com foliolos definidos, respectivamente.

Logo após a aplicação, as partes aéreas das plantas-alvo de feijoeiro e capim-braquiária foram cuidadosamente removidas, com suas folhas devidamente enumeradas, para identificação, conforme seu posicionamento iniciado na base em direção ao ápice. Em seguida, as folhas identificadas foram submetidas à luz negra em ambiente escuro, onde se procedeu à avaliação de distribuição das gotas da pulverização na face superior (adaxial) destas, utilizando-se um critério de escala visual de notas de 0 a 5, adaptado de Palladini (1997), em que a nota zero representa ausência total de cobertura e a nota cinco, cobertura pesada da pulverização (Tabela 7). No caso das folhas do feijoeiro, as notas de distribuição foram geradas por meio da média dos três folíolos pertencentes a cada folha.

A avaliação do depósito da solução traçante nas plantas-alvo foi realizada logo após a avaliação de distribuição das gotas de pulverização, utilizando-se $50 \mathrm{~mL}$ de água destilada em saquinho plástico para lavagem de cada folha das plantas de feijoeiro, assim como para a lavagem de seus pecíolos e caules. A lavagem do traçante das partes das plantas foi feita colocando-as separadamente nos saquinhos e submetendo-as à agitação constante durante aproximadamente 20 segundos. A condutividade elétrica da solução obtida pela água de lavagem foi mensurada utilizando-se um condutivímetro manual, modelo Corning 311, similarmente à metodologia utilizada por Velini et al. (1995), Nogueira (1996) e Tomazela et al. (1997).

O mesmo procedimento de lavagem com $50 \mathrm{~mL}$ de água destilada em saquinhos plásticos também foi utilizado para cada repetição de capim-braquiária, sendo lavada a parte área total das duas plantas em um único saquinho. Em ambas as situações, os saquinhos plásticos e a água destilada foram previamente testados 
quanto à possibilidade de contaminação e interferência da leitura de condutividade da solução, sendo a média de seus valores atribuída como fator de correção da condutividade da solução de todas as repetições dos tratamentos.

Uma curva-padrão de calibração foi ajustada entre a condutividade elétrica da solução e a sua concentração de $\mathrm{NaCl}(\mu \mathrm{L})$, proporcionando a geração de um coeficiente angular da reta (A) com valor de 2,062 e um coeficiente de determinação $\left(\mathrm{R}^{2}\right)$ igual a 0,9999 , respectivamente. O coeficiente angular da reta foi utilizado no modelo citado a seguir, possibilitando, juntamente com a condutividade da água de lavagem e dos saquinhos plásticos, corrigir a concentração da solução traçante de $\mathrm{NaCl}$ pulverizada nas plantas de feijoeiro e capim-braquiária.

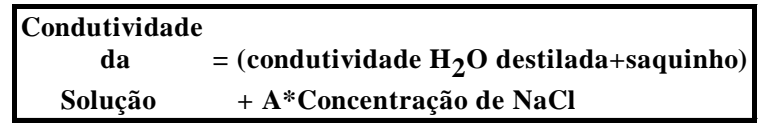

Todas as folhas das plantas-alvo, após lavagem da solução pulverizada, foram submetidas à determinação de área foliar utilizandose um integrador de área foliar e, juntamente com os pecíolos e caules, acondicionadas em estufa de secagem forçada a uma temperatura de $60{ }^{\circ} \mathrm{C}$, por um período de três dias, para determinação da matéria seca. O objetivo desses procedimentos foram determinar a uniformidade entre os tratamentos, extrapolando os valores de condutividade das soluções amostra-

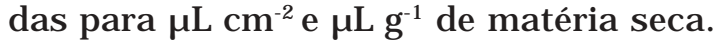

Para estimar a distribuição das gotas de pulverização nas folhas de feijoeiro e capimbraquiária, foram determinadas as porcentagens de amplitude e os coeficientes de variação para cada tratamento. Os resultados originais da deposição média da pulverização dos bicos jato plano e cônico foram convertidos para $100 \mathrm{~L} \mathrm{ha}^{-1}$, de forma que se igualasse a condição de operação de todos os tratamentos.

Os dados de deposição média estimada em relação à área foliar (Tabela 1), matéria seca de folhas (Tabela 2) e pecíolos + caules totais (Tabela 3) das plantas de feijoeiro, assim como da área foliar (Tabela 4) e matéria seca (Tabela 5) de duas plantas de capim-braquiária, foram submetidos à análise de variância pelo teste $\mathrm{F}$ e suas médias comparadas pelo teste t de Student a 10\% de probabilidade.

\section{RESULTADOS E DISCUSSÃO}

Os valores de deposição média e deposição estimada (100 $\left.\mathrm{L} \mathrm{ha}^{-1}\right)$ dos tratamentos em relação à área foliar $\left(\mu \mathrm{L} \mathrm{cm}^{-2}\right)$ e matéria seca $\left(\mu \mathrm{L} \mathrm{g}^{-1} \mathrm{MS}\right)$ total das folhas das plantas de feijoeiro encontram-se dispostos nas Tabelas $1 \mathrm{e}$ 2. Esses resultados indicam que os bicos de pulverização, jato plano e cônico, não apresentaram diferenças significativas na deposição estimada para a área foliar $\left(\mu \mathrm{L} \mathrm{cm}^{-2}\right)$ e matéria seca ( $\mu \mathrm{L} \mathrm{g}^{-1} \mathrm{MS}$ ) total das folhas de feijoeiro, quando submetidos à mesma condição de calda de pulverização. Dessa forma, a adição ou não do surfactante Aterbane BR $(0,5 \% \mathrm{v} / \mathrm{v})$ não influenciou significativamente o desempenho dos modelos de bicos de pulverização estudados no experimento. No entanto, quando a solução traçante foi pulverizada na ausência do surfactante, os bicos jato plano e cônico tiveram aumento de 67,1 e $61,5 \%$ na deposição estimada em relação a área foliar e 106,4 e 66,9\% para matéria seca de folhas totais de feijoeiro, respectivamente, em comparação com os tratamentos com o uso de surfactante.

Para a variável matéria seca de pecíolos e caules totais das plantas de feijoeiro, apresentada na Tabela 3, apenas o bico jato plano, quando na presença do surfactante, proporcionou redução significativa na quantidade estimada de solução traçante depositada, sendo esta inferior à dos demais tratamentos.

Esses resultados evidenciam que a associação do surfactante a qualquer um dos bicos estudados, independentemente do modelo, poderia melhorar a seletividade da cultura do feijoeiro aos possíveis efeitos fitotóxicos de herbicidas aplicados em pós-emergência, haja vista a ocorrência de menor deposição encontrada na cultura em relação a área foliar e matéria seca. Ou seja, o uso de Aterbane BR $(0,5 \%$ de v/v) na calda de pulverização, apesar de não ter influenciado o desempenho das pontas de pulverização, alterou a relação de depósitos, com vantagem para a cultura. Esse fato talvez possa ser explicado pela possibilidade de um escorrimento, ou não-aderência, das gotas de pulverização, proporcionado pelo surfactante Aterbane BR utilizado na solução pulverizada. Para fungicidas e inseticidas, esse raciocínio necessariamente deveria ser invertido, uma vez que o melhor desempenho destes produtos seria encontrado quando não fosse 
utilizado o surfactante, devido à melhor cobertura e proteção das plantas tratadas como alvo e, conseqüentemente, ao menor desperdício de produto aplicado.

Nas Tabelas 4 e 5 encontram-se dispostos os valores da deposição média e deposição estimada (100 L ha-1) em relação a área foliar $\left(\mu \mathrm{L} \mathrm{cm}^{-2}\right)$ e matéria seca $\left(\mu \mathrm{L} \mathrm{g}^{-1} \mathrm{MS}\right)$ de duas plantas de capim-braquiária. Para esta plantaalvo, a pulverização com o modelo de bico jato cônico Conejet (TXVK-4), independentemente da adição ou não do surfactante Aterbane BR $(0,5 \% \mathrm{v} / \mathrm{v})$ na calda de pulverização, proporcionou deposição muito superior àquela com bico jato plano XR Teejet (XR110.02VS). O bico jato cônico Conejet (TXVK-4) proporcionou depósitos significativamente mais elevados de traçante por área foliar das plantas de capim-braquiária (Tabela 4), apresentando-se 1,7 (169,0\%) e 5,5 $(548, \%)$ vezes superiores, respectivamente, quando submetidos à pulverização na ausência ou em adição do surfactante. O mesmo efeito foi observado em relação à deposição do traçante por matéria seca de capim-braquiária (Tabela 5), em que o bico de jato cônico Conejet (TXVK4) superou significativamente o desempenho do bico jato plano XR Teejet (XR110.02VS), sendo 1,5 e 5,0 vezes superior, respectivamente, quando submetidos à pulverização na ausência ou em adição do surfactante.

Tabela 1 - Valores médios de depósito e deposição estimada para volume de $100 \mathrm{~L} \mathrm{ha}^{-1}$, em relação à área das folhas totais de feijoeiro submetidas aos tratamentos. UNESP, Botucatu-SP, 1999 (média de cinco repetições - dados originais)

\begin{tabular}{|l|l|c|c|c|}
\hline \multicolumn{1}{|c|}{ Soluções } & \multicolumn{1}{c|}{$\begin{array}{c}\text { Ponta de } \\
\text { pulverização }\end{array}$} & $\begin{array}{c}\text { Volume } \\
\left(\mathrm{L} \mathrm{ha}^{-1}\right)\end{array}$ & $\begin{array}{c}\text { Deposição média } \\
\left(\mu \mathrm{L} \mathrm{cm}^{-2}\right)\end{array}$ & $\begin{array}{c}\text { Deposição estimada } \\
100 \mathrm{~L} \mathrm{ha}^{-1}\left(\mu \mathrm{L} \mathrm{cm}^{-2}\right)\end{array}$ \\
\hline 1. Sal ${ }^{1}+$ Corante $^{2}+$ Aterbane \\
2. Sal + Corante + Aterbane & Jato Plano & 185 & 1,35 & $0,73 \mathrm{~b}^{4}$ \\
3. Sal + Corante & Jato Cônico & 120 & 0,93 & $0,78 \mathrm{~b}$ \\
4. Sal + Corante & Jato Plano & 185 & 2,26 & $1,22 \mathrm{a}$ \\
\hline F & Jato Cônico & 120 & 1,51 & $1,26 \mathrm{a}$ \\
CV $(\%)$ & - & - & - & $5,99 *$ \\
DMS $(10 \%)$ & - & - & - & 25,93 \\
\hline
\end{tabular}

$\mathrm{Sal}=\mathrm{NaCl} 0,5 \% \mathrm{p} / \mathrm{v}$.

2 Corante $=$ Poliglow laranja $0,5 \% \mathrm{p} / \mathrm{v}+$ Manzate $0,5 \% \mathrm{p} / \mathrm{v}$.

3 Aterbane $=$ surfactante a $0,5 \% \mathrm{v} / \mathrm{v}$

4 Médias, na mesma coluna, seguidas da mesma letra não diferem significativamente entre si.

$*(\mathrm{p}<0,10)$.

Tabela 2 - Valores médios de depósito e deposição estimada para volume de $100 \mathrm{~L} \mathrm{ha}^{-1}$, em relação à matéria seca das folhas totais de feijoeiro submetidas aos tratamentos. UNESP, Botucatu-SP, 1999 (média de cinco repetições - dados originais)

\begin{tabular}{|c|c|c|c|c|}
\hline Soluções & $\begin{array}{c}\text { Ponta de } \\
\text { pulverização }\end{array}$ & $\begin{array}{l}\text { Volume } \\
\left(\mathrm{L} \mathrm{ha}^{-1}\right)\end{array}$ & $\begin{array}{l}\text { Deposição média } \\
\left(\mu \mathrm{L} \mathrm{g}^{-1} \mathrm{MS}\right)\end{array}$ & $\begin{array}{c}\text { Deposição estimada } \\
100 \mathrm{~L} \mathrm{ha}^{-1}\left(\mu \mathrm{L} \mathrm{g}^{-1} \mathrm{MS}\right)\end{array}$ \\
\hline 1. $\mathrm{Sal}^{1}+$ Corante $^{2}+$ Aterbane $^{3}$ & Jato Plano & 185 & 422,37 & $228,31 \mathrm{~b}^{4}$ \\
\hline 2. Sal + Corante + Aterbane & Jato Cônico & 120 & 280,61 & $233,34 \mathrm{~b}$ \\
\hline 3. Sal + Corante & Jato Plano & 185 & 871,77 & $471,22 \mathrm{a}$ \\
\hline 4. Sal + Corante & Jato Cônico & 120 & 467,45 & $389,54 \mathrm{a}$ \\
\hline $\mathrm{F}$ & - & - & - & $5,63^{*}$ \\
\hline $\mathrm{CV}(\%)$ & - & - & - & 34,13 \\
\hline DMS (10\%) & - & - & - & 124,67 \\
\hline
\end{tabular}

$\mathrm{Sal}=\mathrm{NaCl} 0,5 \% \mathrm{p} / \mathrm{v}$.

2 Corante $=$ Poliglow laranja $0,5 \% \mathrm{p} / \mathrm{v}+$ Manzate $0,5 \% \mathrm{p} / \mathrm{v}$.

3 Aterbane $=$ surfactante a $0,5 \% \mathrm{v} / \mathrm{v}$

4 Médias, na mesma coluna, seguidas da mesma letra não diferem significativamente entre si.

$*(\mathrm{p}<0,10)$. 
Tabela 3 - Valores médios de depósito e deposição estimada para volume de $100 \mathrm{~L} \mathrm{ha}^{-1}$, em relação à matéria seca dos pecíolos e caules totais de feijoeiro submetidos aos tratamentos. UNESP, Botucatu-SP, 1999 (média de cinco repetições - dados originais)

\begin{tabular}{|c|c|c|c|c|}
\hline Soluções & $\begin{array}{c}\text { Ponta de } \\
\text { pulverização }\end{array}$ & $\begin{array}{l}\text { Volume } \\
\left(\mathrm{L} \mathrm{ha}^{-1}\right)\end{array}$ & $\begin{array}{l}\text { Deposição média } \\
\left(\mu \mathrm{L} \mathrm{g}^{-1} \mathrm{MS}\right)\end{array}$ & $\begin{array}{l}\text { Deposição estimada } \\
\left(\mu \mathrm{L} \mathrm{g}^{-1} \mathrm{MS}\right)\end{array}$ \\
\hline 1. Sal $^{1}+$ Corante $^{2}+$ Aterbane $^{3}$ & Jato Plano & 185 & 19,54 & $10,56 b^{4}$ \\
\hline 2. Sal + Corante + Aterbane & Jato Cônico & 120 & 17,62 & $14,68 \mathrm{a}$ \\
\hline 3. Sal + Corante & Jato Plano & 185 & 30,18 & $16,31 \mathrm{a}$ \\
\hline 4. Sal + Corante & Jato Cônico & 120 & 19,05 & $15,88 \mathrm{a}$ \\
\hline $\mathrm{F}$ & - & - & - & $3,31 *$ \\
\hline $\mathrm{CV}(\%)$ & - & - & - & 22,46 \\
\hline DMS $(10 \%)$ & - & - & - & 3,56 \\
\hline
\end{tabular}

$1 \mathrm{Sal}=\mathrm{NaCl} 0,5 \% \mathrm{p} / \mathrm{v}$.

2 Corante $=$ Poliglow laranja $0,5 \% \mathrm{p} / \mathrm{v}+$ Manzate $0,5 \% \mathrm{p} / \mathrm{v}$.

3 Aterbane $=$ surfactante a $0,5 \% \mathrm{v} / \mathrm{v}$.

${ }_{4}^{4}$ Médias, na mesma coluna, seguidas da mesma letra não diferem significativamente entre si.

$*(\mathrm{p}<0,10)$.

Tabela 4 - Valores médios de depósito e deposição estimada para volume de $100 \mathrm{~L} \mathrm{ha}^{-1}$, em relação à área foliar de duas plantas de capim-braquiária, posicionadas embaixo de plantas de feijoeiro e submetidas aos tratamentos. UNESP, Botucatu-SP, 1999 (média de cinco repetições - dados originais)

\begin{tabular}{|c|c|c|c|c|}
\hline Soluções & $\begin{array}{c}\text { Ponta de } \\
\text { pulverização }\end{array}$ & $\begin{array}{l}\text { Volume } \\
\left(\mathrm{L} \mathrm{ha}^{-1}\right)\end{array}$ & $\begin{array}{l}\text { Deposição média } \\
\left(\mu \mathrm{L} \mathrm{cm}^{-2}\right)\end{array}$ & $\begin{array}{l}\text { Deposição estimada } \\
100 \mathrm{~L} \mathrm{ha}^{-1}\left(\mu \mathrm{L} \mathrm{cm}^{-2}\right)\end{array}$ \\
\hline 1. Sal $^{1}+$ Corante $^{2}+$ Aterbane $^{3}$ & Jato Plano & 185 & 0,081 & $0,044 \mathrm{~b}^{4}$ \\
\hline 2. Sal + Corante + Aterbane & Jato Cônico & 120 & 0,342 & $0,285 \mathrm{a}$ \\
\hline 3. Sal + Corante & Jato Plano & 185 & 0,158 & $0,085 \mathrm{~b}$ \\
\hline 4. Sal + Corante & Jato Cônico & 120 & 0,275 & $0,229 \mathrm{a}$ \\
\hline $\mathrm{F}$ & - & - & - & $8,47 *$ \\
\hline $\mathrm{CV}(\%)$ & - & - & - & 54,93 \\
\hline DMS (10\%) & - & - & - & 0,0974 \\
\hline
\end{tabular}

Sal $=\mathrm{NaCl} 0,5 \% \mathrm{p} / \mathrm{v}$.

2 Corante $=$ Poliglow laranja $0,5 \% \mathrm{p} / \mathrm{v}+$ Manzate $0,5 \% \mathrm{p} / \mathrm{v}$.

3 Aterbane $=$ surfactante a $0,5 \% \mathrm{v} / \mathrm{v}$.

4 Médias, na mesma coluna, seguidas da mesma letra não diferem significativamente entre si.

$*(\mathrm{p}<0,10)$.

A distribuição das gotas de pulverização na face superior (adaxial) das folhas de capimbraquiária está representada na Tabela 6. Por meio desses dados pode-se afirmar que os tratamentos com bico jato cônico Conejet (TXVK4) apresentaram, em média, os maiores valores de distribuição e uniformidade, sendo superiores aos com bico de jato plano XR Teejet (XR110.02VS). Esse fato é justificado pela menor amplitude e coeficiente de variação da distribuição das gotas pulverizadas pelo modelo jato cônico nas cinco folhas avaliadas, sendo ainda evidente a melhoria de seu desempenho quando associado ao surfactante Aterbane
$(0,5 \%$ v/v). A associação do surfactante à calda de pulverização, aplicada com bico jato plano XR Teejet (XR1 10.02VS), proporcionou redução acentuada da amplitude de distribuição das gotas nas folhas de capim-braquiária, assim como de seu coeficiente de variação, quando comparado com o mesmo modelo de bico na ausência do surfactante, o que também justifica a melhoria de seu desempenho. Esse fato, assim como os demais eventos observados através da distribuição das gotas nas folhas de capimbraquiária, contribui para esclarecer e validar os resultados obtidos na deposição da calda de pulverização. 
Tabela 5 - Valores médios de depósito e deposição estimada para volume de $100 \mathrm{~L} \mathrm{ha}^{-1}$, em relação à matéria seca de duas plantas de capim-braquiária, posicionadas embaixo de plantas de feijoeiro e submetidas aos tratamentos. UNESP, Botucatu-SP, 1999 (média de cinco repetições - dados originais)

\begin{tabular}{|l|c|c|c|c|}
\hline \multicolumn{1}{|c|}{ Soluções } & \multicolumn{1}{|c|}{$\begin{array}{c}\text { Ponta de } \\
\text { pulverização }\end{array}$} & $\begin{array}{c}\text { Volume } \\
\left(\mathrm{L} \mathrm{ha}^{-1}\right)\end{array}$ & $\begin{array}{c}\text { Deposição média } \\
\left(\mu \mathrm{L} \mathrm{g}^{-1} \mathrm{MS}\right)\end{array}$ & $\begin{array}{c}\text { Deposição estimada } \\
\left(\mu \mathrm{L} \mathrm{g}^{-1} \mathrm{MS}\right)\end{array}$ \\
\hline 1. Sal ${ }^{1}+$ Corante $^{2}+$ Aterbane $^{3}$ & Jato Plano & 185 & 31,59 & $17,07 \mathrm{c}^{4}$ \\
2. Sal + Corante + Aterbane & Jato Cônico & 120 & 122,95 & $102,46 \mathrm{a}$ \\
3. Sal + Corante & Jato Plano & 185 & 45,06 & $24,36 \mathrm{c}$ \\
4. Sal + Corante & Jato Cônico & 120 & 71,67 & $59,73 \mathrm{~b}$ \\
\hline F & - & - & - & $8,06^{*}$ \\
CV $(\%)$ & - & - & - & 60,50 \\
DMS $(10 \%)$ & - & - & - & 34,01 \\
\hline
\end{tabular}

$\mathrm{Sal}=\mathrm{NaCl} 0,5 \% \mathrm{p} / \mathrm{v}$.

2 Corante $=$ Poliglow laranja $0,5 \% \mathrm{p} / \mathrm{v}+$ Manzate $0,5 \% \mathrm{p} / \mathrm{v}$.

3 Aterbane $=$ surfactante a $0,5 \% \mathrm{v} / \mathrm{v}$

4 Médias, na mesma coluna, seguidas da mesma letra não diferem significativamente entre si.

$*(\mathrm{p}<0,10)$.

Tabela 6 - Distribuição média das gotas na face superior do limbo foliar de plantas de capim-braquiária através de escala visual de notas (0-5) $)^{1}$, amplitude (\%) e coeficiente de variação (\%) dos tratamentos. UNESP, Botucatu-SP, 1999 (média de cinco repetições - dados originais)

\begin{tabular}{|c|c|c|c|c|c|c|c|}
\hline \multirow{2}{*}{ Tratamentos } & \multicolumn{5}{|c|}{ Distribuição média nas folhas ${ }^{2}$} & \multirow{2}{*}{$\begin{array}{c}\text { Amplitude } \\
(\%)\end{array}$} & \multirow{2}{*}{$\begin{array}{l}\mathrm{CV} \\
(\%)\end{array}$} \\
\hline & $1^{\underline{a}}$ & $2^{\mathrm{a}}$ & $3^{\mathrm{a}}$ & $4^{\mathrm{a}}$ & $5^{\mathrm{a}}$ & & \\
\hline 1.XR Teejet+Traçante ${ }^{3}+$ Aterbane $^{4}$ & 1,2 & 1,9 & 2,0 & 2,1 & 1,7 & 50,56 & 20,02 \\
\hline 2. Conejet + Traçante + Aterbane & 2,6 & 2,9 & 2,7 & 3,1 & 2,5 & 21,42 & 8,73 \\
\hline 3. XR Teejet + Traçante & 1,7 & 0,8 & 1,9 & 1,2 & 0,6 & 108,33 & 45,12 \\
\hline 4. Conejet + Traçante & 1,7 & 1,3 & 1,9 & 1,6 & 1,7 & 37,50 & 13,36 \\
\hline
\end{tabular}

1 Nota $0=$ ausência total de cobertura; nota $1=25 \%$ de cobertura; nota $2=50 \%$ de cobertura; nota $3=75 \%$ de cobertura; nota $4=100 \%$ de cobertura leve; nota $5=100 \%$ de cobertura pesada.

2 Posicionamento das folhas da base para o ápice das plantas.

3 Traçante $=\operatorname{sal}(\mathrm{NaCl} 0,5 \% \mathrm{p} / \mathrm{v})+$ corante $($ Poliglow laranja 0,5\% p/v) + Manzate 0,5\% p/v.

4 Aterbane $=$ surfactante Aterbane BR $0,5 \% \mathrm{v} / \mathrm{v}$.

Para as plantas de feijoeiro, os dados obtidos de distribuição das gotas de pulverização não foram conclusivos e compatíveis com a metodologia utilizada, e esse fato pode estar relacionado à distribuição, ao posicionamento e ao tamanho dos folíolos nas plantas, os quais se apresentam irregulares devido à própria arquitetura e constituição das plantas de feijoeiro.

As informações resultantes da deposição e distribuição da calda de pulverização, para o capim-braquiária, indicam que a opção de associar o modelo de bico cônico ao surfactante Aterbane BR seria a melhor forma de manejo com herbicidas aplicados em pós-emergência desta planta daninha na cultura do feijoeiro
(Figura 1). No entanto, essa informação contradiz a atitude tomada pela maioria dos agricultores, de utilizar somente bicos de jato plano para a aplicação de herbicidas.

Apesar da necessidade de se conhecer melhor o comportamento do espectro de gotas produzidas pelo modelo de bico cônico, quando associado ao surfactante Aterbane BR em pulverizações no campo, principalmente com relação à formação de deriva, este tratamento teoricamente proporcionaria à cultura maior seletividade aos herbicidas aplicados em pósemergência, graças à menor deposição encontrada nas plantas da cultura. Além disso, conseqüentemente, possibilitaria a redução da 
dose de herbicidas para a mesma eficiência de controle, uma vez que as gotas produzidas pelo modelo de bico jato cônico Conejet (TXVK-4) foram eficientemente direcionadas e interceptadas pelas plantas-alvo de capim-braquiária, contornando problemas como, por exemplo, o de efeito guarda-chuva.

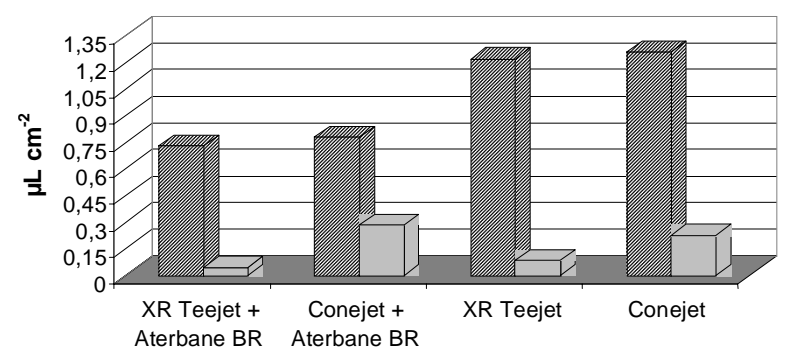

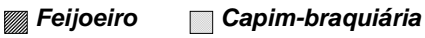

Figura 1 - Depósito estimado para volume de aplicação de $100 \mathrm{~L} \mathrm{ha}^{-1}$ em relação à área foliar de duas plantas de capimbraquiária posicionadas sob uma planta de feijoeiro e submetidas aos tratamentos. UNESP/FCA. Botucatu-SP, 1999.

\section{LITERATURA CITADA}

BRAZEE, R.D.; BUKOVAC, M.J.; COOPER, J.A.; ZHU, H.; REICHARD, D.L.; FOX, R.D. Surfactant diffusion and dynamic surface tension in spray solutions. Transactions of the ASAE, v.37, n.1, p.51-58, 1994.

CHRISTOFFOLETI, J.C. Considerações sobre tecnologia de aplicação de defensivos agrícolas. São Paulo: jun. 1999. (Boletim Técnico, 5) Disponível em: <http://www.teejet.com.br>. Acesso em: 1 dez.2000.

DEUBER, R. Cultura do feijoeiro. In: DEUBER, R. Ciência das plantas infestantes. Campinas: Edição do autor, 1997. v.2, p.101-110

DURIGAN, J.C. Efeitos dos adjuvantes na aplicação e eficácia dos herbicidas. Jaboticabal: FUNEP, 1993. 42p.

HISLOP, E.C.; COOKE, B.K.; HERRINGTON, P.M.; WESTERN, N.M.; WOODLEY, S.E. Efficient use of agrochemicals. Long Ashton Research Station. An. Rep., p.48-49, 1987.

MATUO, T.; NAKAMURA, S.H.; ALMEIDA, A. Efeitos de alguns adjuvantes da pulverização nas propriedades físicas do líquido. Summa Phytopathol., Jaguariuma, v.15, p.163-173, 1989.

Planta Daninha, Viçosa-MG, v.19, n.1, p.103-110, 2001
MATUO, T. Tecnologia de aplicação de defensivos. In: GRAZIANO NETO, F. (Ed.). Uso de agrotóxico e receituário agronômico. São Paulo: Agroedições, 1982. p.103-106.

MILLER, P.C.H. Spray drift and its mesurement. In: MATTHES, G.A., HISLOP, E.C. (Eds.). Application technology for crop protetion. Trowbridge: CAB International, 1993. p.101-122.

NOGUEIRA, H.C. Avaliação da uniformidade de deposição e perdas de calda na utilização de um pulverizador desenvolvido para aplicação de herbicidas em ferrovias. Botucatu: UNESP, 1996. 72p. Dissertação (Mestrado em Agronomia) - Universidade Estadual Paulista, 1996.

PALLADINI, L.A. Efeitos de condições operacionais de um turboatomizador na cobertura de folhas de citros. Jaboticabal: UNESP, 1997. 93p. Dissertação (Mestrado em Agronomia) Universidade Estadual Paulista, 1997.

PIO, L.C. Caracterização de equipamentos adequados para aplicação de herbicidas. In: CONGRESSSO BRASILEIRO DA CIÊNCIA DAS PLANTAS DANINHAS, 21, 1997, Caxambu. Palestras e mesas redondas. Caxambu: SBCPD, 1997. p.155-161.

REVEES, B.G. The rationale of adjuvant use with agrichemicals. In: FOY, C.L. (Ed.) Adjuvants for agrichemicals. Boca Raton: CRC Press, 1992, p.487-488.

SILVA, J.G. Equipamentos e métodos de aplicação de herbicidas. Inf. Agropec., v.8, n.87, p.44-54, 1982.

TOMAZELA, M.S.; MARTINS, D.; VELINI, E.D.; SILVA, M.A.S. Avaliação do depósito de calda de pulverização em Brachiaria plantaginea (Link) Witch: Efeito do volume de aplicação. In: CONGRESSSO BRASILEIRO DA CIÊNCIA DAS PLANTAS DANINHAS, 21, 1997, Caxambu. Resumos.... Caxambu: SBCPD, 1997. p.428.

VELINI, E.D.; OSIPE, R.; GAZZIERO, D.L.P. Procedimentos para instalação, avaliação e análise de experimentos com herbicidas. Londrina: SBCPD, 1995. 42p.

VELINI, E.D.; ANTUNIASSI, U.R.; MARTINS, D.; TRINDADE M.L.B.; SILVA, M.A.S. Utilização da condutividade elétrica para a avaliação do depósito de calda de pulverização em alvos ou folhas. In: CONGRESSO BRASILEIRO DA CIÊNCIA DAS PLANTAS DANINHAS, 20, 1995, Florianópolis. Resumos... Florianópolis: SBCPD, 1995. p.427-428. 